\title{
ARCHÄOLOGISCHER ANZEIGER
}

\author{
$1963 \cdot$ HEFT 2
}

$B E I B L A T T Z U M$

JAHRBUCH DES DEUTSCHEN ARCHAOOLOGISCHEN INSTITUTS

WALTER DE GRUYTER at CO - BERLIN 1963 